\title{
Caring for Dinner in Hospital
}

\section{Mette Holst*, Birgitte Schantz Laursen and Henrik H Rasmussen}

Center for Nutrition and Bowel Disease, Medical Gastroenterology Department, Aarhus University Hospital, Aalborg, Denmark

\begin{abstract}
Better organization may improve quality of care around meal serving in a hospital unit.

Background: The organization of care regarding serving of food, monitoring and assisting patients with meals is a complex nursing task, however, to a low degree investigated. This study was done at request from the department multi professional nutrition team, as nutrition monitoring was difficult to achieve. Furthermore meal serving, especially regarding dinner, was found chaotic and unsatisfying.
\end{abstract}

Aim: To explore practise and organization around meal serving regarding dinner and find reasons for poor monitoring of nutrition intake.

Methods: Observations as well as patient and staff interviews and observation in a department of gastroenterology in 2010 .

Results: Ten patients, six nursing staff and four service staff members were interviewed. Observations were done for nine hours during two days of dinner servings. A positive and helpful attitude was seen. However, lack of time, knowledge, lack of assignment of responsibility and many competing tasks interfered with the meal serving and related tasks. Low priority was given to assisting patients with eating and to documentation of individual nutritional assessment and care. Poor monitoring of nutrition intake was seen, due to insufficient training of service staff and lack of communication of responsibility.

Conclusion: A poor organisation of the overall work was found. The nurses had too many competing tasks. Lack of knowledge, documentation and acknowledgement of importance of own actions, was profound among the nursing-staff regarding nutritional care during dinner serving.

\section{Introduction}

Decreased nutrition intake is related to increased risk of complications and adverse clinical outcomes in patients during hospitalization [1-5]. In the clinical setting, lack of leadership and knowledge among staff including absence of specific guidelines, are amongst barriers for providing optimal nutritional care [6-10]. The nutrition process includes screening for nutritional risk, nutritional assessment, nutrition plan, monitoring and communication [11-13]. Serving of meals, getting patients ready and well positioned for eating are nursing tasks. Furthermore, the process of monitoring food intake, evaluation of food intake and attempts to improve oral intake, as well as attempts to evaluate resistance for eating are tasks moreover carried out by nurses alone or in collaboration with dieticians and physicians. The attention to nutritional care and assistance from nurses has been shown to increase nutrition intake among patients in hospitals [14-18].

Investigations have only to a low degree regarded nutritional practise in assisting patients at meals, and serving of food for patients $[19,20]$. The organization and quality of nursing care regarding serving of food and assisting patients with the meal, is to a low degree investigated. Hence, the need for sufficient knowledge among nurses has moreover been described, in association to screening of nutritional risk and evaluation of nutritional status. However, practise sometimes indicates, that even though nutrition screenings and plans are made to perfection, the direct nutritional care and serving for the individual patient, is limited. The importance of serving and caring for patients at mealtimes may be underestimated [14,20-22]. The reason for initiation of the study was that nutrition records used for bedside monitoring of nutrition intake in this unit of gastroenterology were to a very low degree completed. Especially nutrition intake recordings around dinner were incomplete. This was seen in a larger investigation evaluating clinical nutrition in the whole hospital setting. Improvement, required a closer examination of causes. The missing monitoring around dinnertime made the individual clinical evaluations of nutrition intake too unspecific, and monitoring efforts during day and night shift became worthless. Randomly fulfilled nutrition records, thereby seemed to delay the clinical decision making process, which often prolonged hospitalization.

The overall aim of this study therefore was to explore nutrition practise and organization around dinner, to find reasons for poor monitoring of nutrition intake, and give suggestions for improvement.

\section{Material and Methods}

\section{The clinical setting}

The setting was a Medical Department of Gastroenterology at a Danish University Hospital. The department (26 patients) included gastrointestinal disease, liver-and pancreas disease and patients with short-bowel syndrome as well as other medical diseases (i. e. COPD and heart disease). All bedrooms suited two patients. In the bedroom there was one common dining table, as well as a bedside table at each bed. Regarding nutritional organization, the department had updated guidelines and instructions, a multi-professional nutrition team, involving two nurses, assistant nurse, and a member of the service staff. Furthermore, a dietician, a consultant physician and a nutrition nurse specialist were assigned to the team. The nutrition team all participated actively in the improvement of nutrition practise. On a daily basis, the

*Corresponding author: Mette Holst, Nutrition Nurse Specialist, MCN, Center for Nutrition and Bowel Disease, Medical Gastroenterology Department, Aarhus University Hospital, Aalborg, Denmark, Tel: +45 99326267 / +45 27113236; E-mail: mette.holst@rn.dk

Received June 20, 2012; Accepted July 26, 2012; Published July 28, 2012

Citation: Holst M, Laursen BS, Rasmussen HH (2012) Caring for Dinner in Hospital. J Nurs Care 1:117. doi:10.4172/2167-1168.1000117

Copyright: (๑) 2012 Holst M, et al. This is an open-access article distributed under the terms of the Creative Commons Attribution License, which permits unrestricted use, distribution, and reproduction in any medium, provided the original author and source are credited. 
dietician and the nutrition nurse specialist, at request, assisted the nurses in making the individualized nutrition plans. All patients were routinely screened for nutritional risk (NRS-2002) by nurses on admission. Patients in this department had a $40 \%$ prevalence of nutritional risk by NRS-2002 screening, according to earlier studies [23]. After screening an individualized nutrition plan was made routinely by the nurses. The applied guideline included monitoring of nutrition intake in all risk patients and evaluation by nurse and physician, including the patient on rounds [24].

However, monitoring seemed often overlooked and delayed, especially due to missing data regarding dinner. This delayed the process of optimising nutrition therapy as well as other clinical decision making. Reminders to staff had been given on several occasions, and when meals were delivered to the department from the hospital kitchen, and served by service staff at a counter placed in the dining room. The dining room was placed as an opening in the hallway, in the middle of the department. Patients, who were not confined to bed or chair, had meals served at the counter by the service staff. Patients who were confined to bed or bedroom, and patients who needed assistance with eating, had meals served by nursing staff (registered nurses and nurse assistants) at bedside. Patients, who needed assistance with walking, or wheel-chair, were followed by nursing staff from the patient bedroom into the dining room.

Nurses and nurse assistant had shared responsibility for serving, and for assisting patients at meals. Dinner took place in the evening shift, which was held by three nurses and one nurse assistant. The nursing staff divided themselves in two groups, working in each end of the department. One group had one nurse and one nurse assistant, and the other two nurses. The service staff served meals at the counter and collected the trays from all patients after dinner. These were furthermore occupied with the finishing preparation of the food delivered from the hospital kitchen, dishwashing, as well as cleaning in the department. Service staff was employed in the central cleaning department and not in the clinical department as the nursing staff.

\section{Data collection and analysis}

With the purpose of gaining understanding of actual practise around the meal, there was a need to experience, describe, interpret and understand all activities around dinnertime. In order to be able to look at different angles of the nutrition practise, we used a qualitative triangulation method with a phenomenological hermeneutic approach. This included semi structured interviews as well as observations [25].

\section{Interviews overall}

Semi structured interviews were carried out with patients, nursing staff and service staff. A semi-structured interview guide inspired by Kvale was designed for each participant group, one for patients, one for nursing staff and one for service staff [26]. All interview guides emphasized experiences of the just ended dinner and secondly dinners in the setting in general. Interviews were conducted until data-saturation was achieved.

\section{Patient interviews}

Patients were included by qualitative sampling, for their ability to express themselves, and willingness to share their experiences with having dinner in the department at least one more time than the actual. The internal nutrition team members, including two nurses and the nurse assistant as well as the nutrition nurse specialist, interviewed the patients. Team members were previously trained by the nutrition nurse specialist, who was experienced with the methodology of qualitative interviews.

The patients were asked to elaborate on what was meaningful for them regarding the serving of meals in the department and how they had experienced especially dinner during the actual hospital stay. They were asked to emphasize care, service and nutrition recording more than quality of food. The interviewer took notes, and transcribed a report of meanings right after the interview.

\section{Nursing staff interviews}

Nurses and health care assistants were included by qualitative sampling in order to find nursing staff who were experienced with activities around dinner in the unit, and who were willing to share their knowledge. The interviews took place in an office inside the unit. The interviewer was the nutrition nurse specialist. The headlines of the interviews were written in notes during the interview session. Following, the notes were immediately transcribed to a text of meaning. This text was presented to the participants for correction. A few missing points were added to one of the interviews after correction.

\section{Service staff interviews}

The service staff were included for their ability to share experiences around serving dinner in the unit. The interviewer was the dietician member of the multidisciplinary nutrition team. Notes were taken and transcribed afterwards to a text of meaning.

\section{Observations}

The observations inspired by Raudaskoski, were done for nine hours, before, during and after two evening meals, in the dining room and the patient bed rooms respectively [27]. The observers were the nutrition team service staff representative (chef by education) and the nutrition nurse specialist (researcher). Since many of the evening shift nurses and nursing assistants worked every second week, observations were done across two weeks, to ensure that differences in staff's attitudes were covered. The two observers divided their observation areas. The first week, the service staff representative made observations in the dining room, and the nutrition nurse specialist made observations in the patient bed rooms. The following week, they changed places. No communication around the observations took place in between the two sessions. The common agenda for the observers was to open-mindedly see what went on around dinnertime. Both took the role of the non-participating observer, and seated themselves at the common table in the bedroom, or on a chair in the corner of the room. Both moved a few times between the bedrooms chosen for observation. Notes were taken and transcribed right after the session. Transcriptions were kept closed until all data had been collected and analysed separately.

In the living room the observations covered all angles from the three dining room tables, the service counter, as well as the traffic back and forth to the area. The observer started her observations half an hour before the meal arrived to the unit, and continued until half an hour after the trolley had left with the dishes.

For observations in the patients' bed rooms, the investigator spent the hour before the meal arrived to the unit, to choose bedrooms with patients who were confined to bed or chair. Furthermore, the hour before the actual mealtime, was used to have a glimpse at eventual preparations made for dinner in the bedrooms. The observers had 
each chosen two respectively three patients across two bedrooms, for observation. The observation study in the bedrooms thereby was focused on five patients.

\section{Data Analysis}

The transcribed data was re-read in common between the investigators for understanding. Following, the material was coded by the nutrition nurse specialist (researcher) into units of meaning to the research questions. Themes conducted were discussed between the observers and interviewers, who had common understanding of the findings and themes.

The quotations presented in the result section represent these themes by typifying the data. Quotations were translated into English by the author and confirmed by co-authors. All the materials were analysed, in the phenomenological hermeneutic framework and following discussed and concluded upon together [28].

\section{Ethical considerations}

The study was conducted according to the rules of the Helsinki Declaration of 2002. The study was put forward to the local ethic committee. Patients as well as staff included were kept anonymous to others than the single observer and interviewer.

\section{Patient interviews}

Before inclusion, the patients' ability to participate was discussed with the nurse in charge. The patients were given written and oral information about the interview. The patients gave written consent to participate in the study and to notes being taken during the interviews. The participants were informed that they at any time before or during the interview could withdraw from participation.

\section{Staff interviews}

The service- and nursing staff at request for interviews were informed about the study, and asked to participate in an interview. The time and setting was arranged individually.

\section{Observations}

The patients in the chosen bedrooms were informed that non participating observations were done as a part of a quality insurance programme about unit activities. They were told that they could, at any time, give notice if they did not want the observer around. None had objections.

The service and nursing staff at work on the evenings of observation were informed by the head nurse, that a study about nutritional care in practise was taking place. This was regarded positively by the staff with kind and welcoming remarks. Both investigators wore civil clothes underneath a uniform top, as well as identification cards, to make sure that everybody felt safe, and to prevent from misunderstandings from patients needing assistance.

\section{Results and Findings}

The patient interviews took place right after dinner during two evenings. Ten patients, eight women and two men with an age range between 25 and 77 years, were included in the study. Participants had been hospitalized ranging from two to nineteen days. Four nurses and two health care assistants participated in the interviews. Of the service staff, three were interviewed. Figure 1 illustrates the methodology.

The units of meaning identified in interviews, repeated themselves in the observation study, and were clustered into the following three
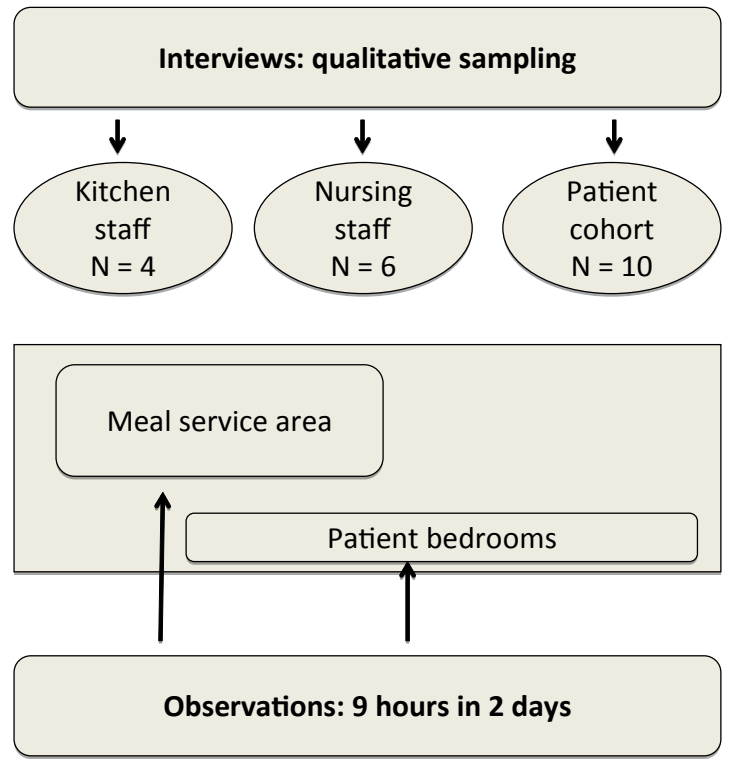

Figure 1: Data collection by qualitative triangulation methodology

significant themes:

\section{Aesthetics' and service}

Organising the work

\section{Professionalism and focus}

In real life, the themes would not be divided, but in order to reach clarity we described the themes separately. The findings from both the interviews and the observations are presented together.

\section{Aesthetics' and service}

The patients overall found that the nursing staff as well as the service assistants were kind and helpful. Dinner was found to be served at least half to an hour too early, since it was short after the in-between afternoon snack.

Patients sometimes felt the need to leave the dining room due to visible drain bags which were found repulsive. They also found discomfort towards the very sick people who were sometimes there. One patient expressed it in this way:

"It is not always nice to eat with these far too sick patients in the dining room. The faeces and drain bags there are disgusting".

In the bedrooms, the patients found that old beverages and food was not cleared from the bedside tables. They passed remarks about the staff not clearing it away. This was found unappetizing. The observations supported the comments made by the patients. The bed side tables were messy and dirty. Old magazines and vomit containers filled with hair combs, toothpaste and other stuff, were bundled up. Left over beverages, were left at the tables, and some had spilt juice and coffee on the bedside tables. In the observed patients, this was not cleared, but only pushed aside by the nursing staff, before they left the dinner tray on the table.

As to the food the patients found that it was overall quite nice, and that they were offered alternatives, if nothing they felt like eating was served for dinner. Portion sizes were mentioned by all patients, and evaluated very differently. Some found it nice, that they did not have 
too large portions served, and others, that the portions were far too large. One patient said: "Imagine the portion size served to you by a French gourmet chef. That's the size of portion I want". Special diets that had been requested for the specific patient, was mentioned as being to a low degree delivered, even though the request had been made by their dietician. This was a source for frustration for patients who had an expectation of getting what was ordered especially for them: "The things ordered especially for you are often missing. My stomach resists wholemeal, so I order plain rye bread. Only it is never delivered. Try eating mackerel on white bread. Simply doesn't work".

Patients found that they could often be offered an extra dish. Mostly though, all the "good stuff" would be far gone by the time they were offered extras, so they did not find that having extras were actually an opportunity.

The service staff was seen as caring, kind and indulgent. The hygiene in the dining room was impeccable, and the servings were sought to look appetizing. There seemed to be a good atmosphere and collaboration among service staff, nursing staff and the patients. Trays were carried to the tables and chairs were pulled out for the patients who seemed to be needing assistance, without patients having to ask the staff for help. Service staff as well as nursing staff encouraged patients to have something to eat, if they seemed reluctant.

On the first evening, nine patients dined in the dining room and the second evening thirteen patients had their dinner there. The impression of this area was that no attempts had been taken to create pleasant surroundings. There was no table cloth, or anything done for tableware. Most patients in the dining room were properly dressed in hospital or private clothes; however a couple of patients wore dirty gowns and had visible drain- and urine bags. Generally a good atmosphere of small talk seemed to dominate around the tables.

Just before dinner was served, the patients were informed by the nurse assistant who stuck her head into the bedrooms, and said that dinner was ready. At the same time she motivated the patients to go out to the dining room, and helped a few patients get out of bed and prepared to go.

\section{Organising the work}

During the evening shift, the nursing staff was grouped into two geographically from each end of the ward and furthermore into tasks. The task who undertook practical care for the patients consisted of one nurse, and one nurse assistant. The others took care of other administrative nursing work. This difference came clear during the interviews, where these divided themselves according to the job they took care of during the shift. The administrative nurses found that they had many competing tasks around the time of the meal preparation and serving. These many tasks made them not quite able to be present, and to involve themselves in the direct patient care. One of the nurses put it this way: You really want to help on the floor, but you simply can't make it. There is a lot of simultaneous things to do around that time; IV-medication, relatives and phones. The time of the evening round varies. Sometimes it is half ways through dinner.

Within the two hours of their shift before the evening meal was served, they had to have an update on the patients, finish tasks started by the day team, answer phone calls from relatives and service departments, assist physicians and others in clinical investigations, meet patient requests, talk to relatives visiting after work, as well as prepare and provide medication for IV and oral medication rounds. They found this time of their schedule very stressful, and found themselves insufficient, when the patient carers needed their help in positioning the bedridden patients.

The patient carers usually started a round through the patient bedrooms an hour before dinner was served. They asked the bedridden patients what they would like to eat from the day's menu. Then they would take notes, so that it would be quicker for them to bring it to the patients during the short meal time. On the same round they would seat the patients ready for eating, to the extent possible. Meanwhile they found, that the menu served, did frequently not match the menu at the menu card distributed beforehand, and their efforts to optimise time, was often wasted: "Often happens that the menu doesn't match the served. Then you will have promised the patient something that is not there, and you will have to take the tour again".

Furthermore, they found it difficult to make their way through the seating of the patients, since they could often not get a hand from a colleague when needed. They found that documentation around good positioning in patients' records was rarely seen or done by themselves either. Documentation for the order for special diets from the kitchen was also hard to find in patient records, so they did not know when to look for special food and when to ask the patients what they wanted. At 5 O'clock p. m. the dinner was ready to be served. Serving was handled by the service staff at the counter for half an hour. After that, the nursing staff was still able to get food for their patients at the counter for 15 minutes. At a quarter to six, the nursing staff went for their own dinner break inside the unit. Five minutes after, the food-carriage left the unit. Another half hour later, all the dishes were cleared from the unit by the service staff and the late meal was organised at the counter. The service staff who served the meal at the counter stood on one side of the counter, and the patients and the nursing staff getting food for patients were in line on the other side, and served across the counter. They were able to see the drinks and serve themselves with these, but not able to see the hot food in the heating carriage, on the other side of the counter. Both nights, the menu card placed on the counter did not totally match the food served, and special diets that had been ordered in the kitchen, were not delivered accordingly. This caused some interruption, as the service staff had to leave the counter, to find something else for the patients. The service staff was very happy with the task of serving food to the patients. They found that the patient contact during the meal serving was their absolute favourite task.

Service staff did not have any knowledge of the diversity in food densities delivered for nutrition risk patients and patients not at risk of undernutrition. They therefore gave the different foods randomly to the patients. It occurred that they usually never used the "normal-diet" (low density food recommended for non nutritional risk patients). They generally found they had fair time to do their job.

\section{Professionalism and focus}

Many simultaneous things were done around the patients, while these were asked by the staff, what they would like to eat. Oxygen catheters were replaced and saline drips were set for speed. One patient was asked what he wanted to eat, while he was having a diagnostic ultrasound examination done by the physician. He did not want anything. After the examination, the nurse came back and asked him again. At that time, he was laying half ways on the side, in the rear end of the bed. He agreed to have a dessert. The nurse left him while he was still lying in this awkward position. When the nurse returned, she tried to help him to sit upright, but she did not manage to seat him properly by herself, so she had to get help from one of her colleagues. By the time they got the patient seated, he was exhausted, and did not eat anything at all. Another, quite large and obviously heavy patient was sitting in an 
armchair when the nurse came to ask what he wanted for dinner. His behind had slid forward so he was sitting quite laid back in the chair. When the nurse delivered the food, she noticed this, pulled his torso forward, and put a pillow in behind him. This resulted in him sliding even more forward with his behind. The nurse did not mention this and did not take any initiatives to improve this positioning. She pulled the table with the tray holding the main dish towards him. From the position it was very hard for him to eat, as he had to balance the food, including peas with a fork, a long distance over his corpus to the mouth. There was also a dessert. This dessert was however placed on the top of the shelf connected to the bedside table, so the patient had no chance of reaching it. When the tray was removed 45 minutes later, he had still not eaten more than a few forkful of his meal.

An old lady was observed in her bed. On request from the nurse, she told that she did not want anything to eat. However, the nurse got her encouraged to receive a dessert. The patient was seated properly, and the nurse left her with the dessert in front of her. She was not asked whether she was able to help herself. When the tray was collected, nothing had still been eaten. Many of the patients had visible food recording sheets attached to their bed or bedside table. Some patients filled these in themselves. It seemed that most of the patients who were served by the nurses or nurse assistant, had whatever was served, written on the sheet. When the trays were taken out, nothing was however written on the sheet. Patients, who went to the dining room and did not write on the sheet themselves, had nothing recorded. The interviews with the service staff revealed, that they were not aware of being involved in the nutrition recording, and did not have any knowledge of how to do this. They found that most patients had food left on their plates, when they collected these at the tables and in the patient bed rooms. Before and during dinner, more patients were drinking quite much water and soft drinks. No guidance about this matter was done. Only one patient in the bed rooms was offered milk selectively. At the counter, milk was only given to patients who asked for it themselves. Nobody were offered oral supplement drinks with their meal, however more patients had these left on the bedside tables from earlier servings.

\section{Discussion}

This study was undertaken at request from a multidisciplinary nutrition team, for improvement of nutritional practise, especially regarding nutrition recording around dinner. By qualitative methodology triangulation, an evaluation of practise around dinner was made. Members of the research team to some extent all had affiliation to the department. This risk of bias due to preconceived beliefs has been sought diminished, by bracketing, and through support from the last author of this article, who had no affiliation to the department. As in all observation studies, there is a risk of bias by patients and staff acting differently because of the presence of the observer. This bias was sought limited by the information given beforehand.

The study generated three themes. These are of course interdependent, and will be discussed together.

Interviews as well as observations found a nice and inviting tone among staff and patients respectively, around dinner. Efforts were made to make the patients feel welcome in the dining area, especially regarding the serving of food, and trying to make it easy for the patients to sit in the dining area. Service staff was to at high degree to thank for this positive atmosphere. Former studies have found that service staff was positively regarded because they offered an important opportunity for "normal" discourse with a non-medical person [14]. However, delicacy in tableware and the patients' appearance were not concerned. When some patients appeared repulsive to others, this kept those away. Only half or less of the patients chose to eat in the dining room, even though more of the patients were obviously able to, since they chose to fetch their food and take it back to their bed room. Encouraging patients to eat together could eventually be strategic by terms of mobilization and increasing appetite by getting out of bed, visualizing the food, and socializing with others. A study from United Kingdom showed that surgical and elderly patients and those with physical disabilities experienced greatest difficulty accessing food, whereas younger patients were more concerned about choice, timing and the delivery of food [17]. The observers found that more patients would have been able to use the dining area, if aesthetics was held around making a nice table, and a dress code, effectuated by help to individuals, from the nursing staff. The food was moreover considered of good quality, and some patients felt they would have liked to have another portion, if some of their favourites had been left for a second round. Dinner was served quite early, compared to a daily standard Danish family dinner. This practise was explained by the leader of the production kitchen as an economic strategy, since kitchen staff would be more expensive during later hours. Furthermore, dinner was served close to the time of the afternoon in-between meal. This was reflected by the patients, and could moreover probably influence many of the organizational problems there seemed to be. Earlier studies in the same department, including other departments in the same hospital, reflect, that the short time between meals, may be a barrier for sufficient nutrition intake [3]. Unsuitable serving times, has in another study been revealed as a barrier for accessing food in hospitals [17]. The administrative working nurses had many competing tasks, and were therefore not at all free to help their colleagues in positioning the patients and serving them. The poor positioning of the patients for eating might have been solved, if there were two people to take care of it rather than one.

The largest problems for the administrative nurses were the many competing tasks, which made it impossible for them to help in the direct patient care. The many competing tasks however also showed in the focus of the direct nutritional care, where many things were done, while asking the patients what they would like to eat. Diagnostic investigations and correction of oxygen catheters in the nose while being encouraged to eat, could limit the appetite. Protected mealtimes seem to be hard to achieve, however some benefits have been found [29].

Though there was a positive attitude and encouragement of patients to eat, there was a lack of professional guidance of what to eat and drink. No thoughts were given to protein intake. Regarding the well-known frequency of nutrition risk patients in the speciality, guidance should be considered in organising the serving of the meal for patients $[6,20]$. Furthermore, the service staff was not aware that nutrition recording was a part of their task, neither, how to do so. Nutrition recording demands a little training, and this was not provided for the service staff. Furthermore it is crucial to know what was put on the plate to be able to see how much was eaten- not only regarding volume, but also the density of food needs to be taken into consideration, if monitoring of nutrition intake should be done aiming at clinical assessment and decision-making. The service staff had no circumstances to do the task. These seemed to be the obvious reasons why nutrition recording at dinnertime did not function in the unit.

A logistic problem appeared somewhere between the hospital kitchen and the deliveries at the department, regarding menus and special diets. This problem seemed to be a source for frustration for patients who are known to have little appetite, as well as lost time for the service and nursing staff. In the patient bed rooms, tables were left messy and unappetizing. This might influence appetite; however 
appetite was not investigated in this study. Tidying the tables could maybe have been done, when the staff went through the rooms asking the patients what they wanted to eat, or telling that dinner was ready. This could not be a very time consuming task, if organized properly, and might have been done by service staff. A good structure for nutrition including guidelines, has formerly been shown to be connected to positive attitude and good practise towards nutrition, however, this was at the level of screening and planning nutritional therapy [7,29]. The organization of care in this departments evening shift did not seem to allow thoughtful nutritional care. The problem seemed to not only involve the department, but also the total logistic in the meal service and organization of the work. While the service staff found they had fine time to do the job, this could be related to the understanding of the work to be done. Food recordings were supposed to be done by the staff who served the portions. This seemed logistically correct to do, for patients who could not do it themselves. Nevertheless, the people in charge of this task were not skilled with it, neither aware of the task. The same staff reflected in the interviews, that most patients on a daily basis, had food left on their plates. They encouraged the patients to eat in a very positive manner, but were not aware of the different food densities available for different nutritional risk and non-risk patients, and they did not advise patients what to drink, though milk and oral supplements were available. This obvious lack of knowledge could be related to the lack of education in the group of service staff, and to the differences in affiliation of the groups. However the same lack of professional advice was seen in the nursing group, since only one of the patients was observed being served milk for dinner, even though this could increase energy and protein intake in the nutritional risk patients. Furthermore, making eating possible in the bed rooms was not exclusively considered, since patients were not seated appropriately $[17,30]$.

The lack of documentation for positioning and need of assistance in patient records, as mentioned by nurses in the interviews, repeats itself in the nursing care seen given to the patients these evenings. Eating assistance was not mentioned by any of the staff or the patients, and however assistance seemed appropriate regarding better positioning of the uncomfortable man in the armchair who was not able to eat due to his positioning, or eating assistance, as could be the need in the old lady, these eventual needs were ignored. Meanwhile the staff went to dinner themselves, without checking if any of the patients were not on their way with eating. The nursing staff did not come back to the patient bed rooms before the trays were taken out, which furthermore gave them no opportunity to acknowledge, that their patients did not eat, or to help and guide them. Interactions between patients and staff regarding meals, has formerly been shown to increase nutrition intake [31,32]. Furthermore, another study showed that nurses can be enabled to make changes to their practice that have a positive impact on both the mealtime experience and wider patient care [33]. The lack of documentation would therefore naturally repeat itself to the next meal, as there was no knowledge to share.

The methodology for evaluation of clinical practise used in this study, allows the unit to look at actual own practise. The idea of involving the nutrition team in the data collection was to benefit their reflection of practise and to secure an affiliation to an eventual implementation process afterwards. The inclusion of the nutrition team in the patient interviews as in the observation demanded some training of the involved parties. The study could not be done without the researcher teaching the included staff in conducting the interviews, and handling the interpretation of the data. Regarding the implementation process, the involvement of a unit leader with economic decision abilities was important.

\section{Strengths and Weaknesses of the Study}

This study only regarded service at dinnertime, as this focus was the request from the unit multi-professional nutrition team. We find however that the attitudes and recurring problems can be transferred to meals during the daytime, where many concurrent activities take place. Observations in this study were done from two very different professional angles. Following, the themes conducted from the observations were discussed between the observers. Both had common understanding of the findings and themes. The observation study only reflects the practise, at the exact time of the study. Qualitative interviews, as in this study, are characterized with a smaller sample size in a certain context. The informants are selected by purposeful sampling. The selection of patients was done in cooperation with the care team around the patient, which ensured that the patients were actually able to participate. The data expresses a subjective content of meaning to the interviewed person at the time and in the actual context. Qualitative interviews are not intended to be validated with generalizability towards a larger population. Data are validated by internal analysis. The validity of qualitative interview and observation studies is seen by the understanding it brings to the subject in similar populations.

\section{Conclusions}

The main conclusions found in this study were that a lot of time was spent regarding the dinner in the unit, however the outcome, as to focusing on nutritional nursing care that would make the nutritional risk patients eat more and better, seemed low. This seemed due to poor organization of the overall work around dinner time and meal service, including the timing of meal and other tasks. Lack of knowledge including, lack of acknowledgement of the importance of own actions and neglect, was profound among the staff at all levels. The reason for poor monitoring of nutrition intake was insufficient training of staff and communication of responsibility.

\section{Perspectives}

A good structure for nutritional matters, including guidelines, has formerly been shown to be connected to positive attitude and good practise. However, this has moreover been regarded the level of screening and planning nutritional therapy. Better organization and training of staff might also be the solution for giving better practise and attitude regarding nutritional care, including nutritional assessment, patient centred help, pleasant surroundings and communication in this unit.

\section{References}

1. Beier-Holgersen R, Boesby S (1996) Influence of postoperative enteral nutrition on postsurgical infections. Gut 39: 833-835.

2. Cederholm T, Jägrén C, Hellström K (1995) Outcome of protein-energy malnutrition in elderly medical patients. Am J Med 98: 67-74.

3. Holst M, Mortensen M.N., Jacobsen B.A., Rasmussen HH. (2010) Efficacy of serving bed side in-between meals - an intervention study in three medical departments. The European e-Journal of Clinical Nutrition and Metabolism 5 e30-e36.

4. Jie B, Jiang ZM, Nolan MT, Efron DT, Zhu SN, et al. (2010) Impact of nutritional support on clinical outcome in patients at nutritional risk: a multicenter prospective cohort study in Baltimore and Beijing teaching hospitals. Nutrition 26: $1088-1093$. 
5. Johansen N, Kondrup J, Plum LM, Bak L, Nørregaard P, et al. (2004) Effect of nutritional support on clinical outcome in patients at nutritional risk. Clin Nutr 23: $539-550$

6. Lassen KO, Kruse F, Bjerrum M, Jensen L, Hermansen K (2004) Nutritiona care of Danish medical inpatients: effect on dietary intake and the occupational groups' perspectives of intervention. Nutr J 3: 12.

7. Holst M, Rasmussen HH, Unosson M., The Scandinavian Nutrition Group. (2009) Well-established nutritional structure in Scandinavian hospitals is accompanied by increased quality of nutritional care. The European e-Journal of Clinical Nutrition and Metabolism 4: e22-e29.

8. Mowe M, Bosaeus I, Rasmussen HH, Kondrup J, Unosson M, et al. (2008) Insufficient nutritional knowledge among health care workers? Clin Nutr 27 196-202.

9. Patel MD, Martin FC (2008) Why don't elderly hospital inpatients eat adequately? J Nutr Health Aging 12: 227-231.

10. Rasmussen HH, Kondrup J, Staun M, Ladefoged K, Lindorff K, et al. (2006) A method for implementation of nutritional therapy in hospitals. Clin Nutr 25: 515-523.

11. Teitelbaum D, Guenter P, Howell WH, Kochevar ME, Roth J, et al. (2005) Definition of terms, style, and conventions used in A.S.P.E.N. guidelines and standards. Nutr Clin Pract 20: 281-285.

12. Lochs H, Dejong C, Hammarqvist F, Hebuterne X, Leon-Sanz M, et al. (2006) ESPEN Guidelines on Enteral Nutrition: Gastroenterology. Clin Nutr 25: 260274.

13. Kondrup J, Allison SP, Elia M, Vellas B, Plauth M; Educational and Clinical Practice Committee, et al. (2003) ESPEN guidelines for nutrition screening 2002. Clin Nutr 22: 415-421.

14. Johns N, Hartwell H, Morgan M (2010) Improving the provision of meals in hospital. The patients' viewpoint. Appetite 54: 181-185.

15. Lassen KO, Kruse F, Bjerrum M (2005) Nutritional care of Danish medical inpatients--patients' perspectives. Scand J Caring Sci 19: 259-267.

16. Naithani S, Thomas JE, Whelan K, Morgan M, Gulliford MC (2009) Experiences of food access in hospital. A new questionnaire measure. Clin Nutr 28: 625-630.

17. Naithani S, Whelan K, Thomas J, Gulliford MC, Morgan M (2008) Hospital inpatients' experiences of access to food: a qualitative interview and observational study. Health Expect 11: 294-303.

18. Pedersen PU (2005) Nutritional care: the effectiveness of actively involving older patients. J Clin Nurs 14: 247-255.

19. Dickinson A, Welch C, Ager L, Costar A (2005) Hospital mealtimes: action research for change? Proc Nutr Soc 64: 269-275

20. Pedersen PU, Tewes M, Bjerrum M (2012) Implementing nutritional guidelines -- the effect of systematic training for nurse nutrition practitioners. Scand J Caring Sci 26: 178-185.

21. Holst M, Rasmussen HH, Laursen BS (2011) Can the patient perspective contribute to quality of nutritional care? Scand J Caring Sci 25: 176-184.

22. Xia C, McCutcheon H (2006) Mealtimes in hospital--who does what? J Clin Nurs 15: 1221-1227.

23. Holst M, Rasmussen HH, Mortensen MN, Lindorff-Larsen KG, Beermann T (2011) PP170-MON Improving Communication in Nutritional Practice: An Intervention Study. Clinical Nutrition Supplements 6: 178

24. Kondrup J, Rasmussen $\mathrm{HH}$, Hamberg O, Stanga Z; Ad Hoc ESPEN Working Group (2003) Nutritional risk screening (NRS 2002): a new method based on an analysis of controlled clinical trials. Clin Nutr 22: 321-336.

25. Holloway I (2005) Qualitative Research in Health Care. McGraw-Hill International, London.

26. Kvale S (1997) Interview: en introduktion til det kvalitative forskningsinterview. (1st Edn), Hans Reitzel Copenhagen.

27. Raudaskoski P, Hastrup K (2010) Observationsmetoder In: Brinkmann S, Tanggaard L, editors. Kvalitative metoder, en grundbog. (1st edn), Hans Reitzels Forlag, Copenhagen.

28. Tanggaard L, Brinkmann S (20007) Interviewet: samtalen som forskningsmetode. In: Tanggaard L, Brinkmann S, editors. Kvalitative metoder en grundbog, Hans Reitzels Forlag, Copenhagen.
29. Hickson M, Connolly A, Whelan K (2011) Impact of protected mealtimes on ward mealtime environment, patient experience and nutrient intake in hospitalised patients. J Hum Nutr Diet 24: 370-374.

30. Norman K, Kirchner H, Freudenreich M, Ockenga J, Lochs H, et al. (2008) Three month intervention with protein and energy rich supplements improve muscle function and quality of life in malnourished patients with non-neoplastic gastrointestinal disease--a randomized controlled trial. Clin Nutr 27: 48-56.

31. Dubé L, Paquet C, Ma Z, McKenzie DS, Kergoat MJ, et al. (2007) Nutritional implications of patient-provider interactions in hospital settings: evidence from a within-subject assessment of mealtime exchanges and food intake in elderly patients. Eur J Clin Nutr 61: 664-672.

32. Jefferies D, Johnson M, Ravens J (2011) Nurturing and nourishing: the nurses role in nutritional care. J Clin Nurs 20: 317-330.

33. Dickinson A, Welch C, Ager L (2008) No longer hungry in hospital: improving the hospital mealtime experience for older people through action research. J Clin Nurs 17: 1492-1502. 